\title{
Evaluation of Soft Tissue Landmarks Using Holdaway Analysis among Southern Rajasthan Population in Various Skeletal Malocculsions
}

\author{
Rashmi Metgud ${ }^{1 *}$, Priya Tiwari ${ }^{1}$ and Gayathri Ramesh ${ }^{2}$ \\ ${ }^{1}$ Pacific Dental College \& Hospital, PAHER University, Udaipur, India \\ ${ }^{2}$ Rama Dental College, Kanpur, Uttar Pradesh, India
}

\begin{abstract}
Aims and objective: Study comprised of 80 individuals with 20 each in every group with age ranging between 20 to 55 years. Ten linear and angular parameters were measured on lateral cephalometric radiographs. Statistical analysis was carried out for each variable using student' $t$ ' test.

Result: The results showed that the $\mathrm{SN}-\mathrm{H}$ line and $\mathrm{H}$ angle was found more in skeletal class II males and skeletal convexity was more in skeletal class II female on intergroup comparison.. In the present study Rajasthan population with skeletal class II were observed to have a significantly protruded mandible. When values of Southern Rajasthan population were compared with Hold away norms, skeletal class I in the study reveal that values obtained for SK convexity, ULT, and $\mathrm{H}$ angle were more than that of Holdaways norms. This suggests that Southern Rajasthan population have a more convex profile and also protruded mandible with thick upper lip.
\end{abstract}

Conclusion: It has been concluded that Rajasthani population standards for Holdaways analysis was found to be statistically different from other ethnic groups. Considering such standards for the studied population would aid in better diagnosis and treatment planning.

Keywords: Forensic facial reconstruction (FFR); Skeletal convexity (SC); Holdaways analysis

\section{Introduction}

A person's ability to recognize a beautiful face is innate, but translating this into defined treatment goals is problematic. Recognizing beauty is not practiced nor is it difficult. The perception of beauty is an individual preference with cultural bias. Rules governing why a face is beautiful are not understood nor are required for anyone to say that a face is beautiful. Artists and health professionals have attempted to define and recreate an ideal. They recognize beauty, yet objective standards are difficult, despite unending attempts to clarify this concept. As health professionals have increased their ability to change faces, the necessity to understand what is and is not beautiful has intensified. With the advent of cephalometric head films, various analyses were developed in an attempt to qualitate and quantitate esthetic facial profiles. Downs attempted to use hard tissue measurements to analyze profile imbalance to differentiate between good and poor dentofacial profiles [1].

The modern society considers facial attractiveness as an important physical attribute. Unconsciously tend to associate desirable personal qualities (such as intelligence) and social ability with attractive faces. The relevance of facial esthetics in dentistry has gained great attention in recent times. An attempt to qualitate and quantitate esthetic facial profiles. However the primary correction aimed was of the dento-alveolar structures, under the tacit belief that the soft tissue improvement would necessarily follow that in the hard tissues. However, it was realized that this did not always happen. The response of the soft tissue movement to the hard tissue could be quite variable. This gave an impetus to the development of soft tissue analyses.

The success of orthodontic treatment is frequently related to the improvement gained in the patient's facial appearance, which includes the soft tissue profile and since there is considerable variation in the soft tissue covering the face, misleading conclusions can be produced if diagnosis and treatment planning are based on dental and skeletal measurements alone, therefore, analysis of the soft tissue facial profile and its comparison with standard soft tissue profile measurements are necessary in all medical specialties that can change facial traits [2].

Forensic facial reconstruction (FFR) is an attempt to reproduce a likeness of the facial features of an individual, based on characteristics of the skull, for the purpose of individual identification. It is often conducted by a three dimensional building up of the face on a skull with artistic clay using standard soft tissue thickness (STT) values and other anatomy based rules. Producing a face from the skull relies on the relationship between the soft tissue covering of the skull and the underlying bony features. For this, STT norms for different ethnic and racial groups have been established using Cephalometrics and most investigators have concluded that there are significant differences among these groups [3]. Hence this indicates that normal measurements for 1 group should not be considered normal for every other races or ethnic groups. Therefore, it is important to develop individual standards for each population and different racial groups must be treated according to their own characteristics.

In reference to such practical need of soft tissue evaluation, many assessment methods of soft tissue profile were introduced including [4], Holdaways [1956], Ricketts [1957], esthetic plane and Burstone's [1959] soft tissue analysis.

*Corresponding author: Dr. Rashmi Metgud, Professor and Head, Departmen of Oral and Maxillofacial Pathology, Pacific Dental College and Hospital, PAHER University, Udaipur, India, Tel: 91-9571258482; E-mail: Drmetgudrashmi@gmail. com

Received October 07, 2014; Accepted November 27, 2014; Published December 02, 2014

Citation: Metgud R, Tiwari P, Ramesh G (2015) Evaluation of Soft Tissue Landmarks Using Holdaway Analysis among Southern Rajasthan Population in Various Skeletal Malocculsions. J Forensic Res 6: 258. doi:10.4172/2157. 7145.1000258

Copyright: ( 2015 Metgud R, et al. This is an open-access article distributed unde the terms of the Creative Commons Attribution License, which permits unrestricted use, distribution, and reproduction in any medium, provided the original author and source are credited. 
Amongst which Holdaways (1983) has attempted not only to quantify soft tissue features contributing to better treatment planning, but also has addressed the main profile characteristics of the lower and middle third structures and also relates its finding to the facial upper third.

Hence this analysis was adopted in many practices in several studies to report the cephalometric soft tissue findings of different ethnicities [5]. Inspite of having different norms set for different races \& ethnic groups, it has been reported that mean facial soft tissue thickness between two skeletal classes is different.

However, facial reconstruction in the forensic field uses one measure of mean thickness for each anthropometric point across all skeletal malocclusions [1]

Hence to obtain more accurate investigation results a measure of thickness of each skeletal class at point for which thickness differs significantly needs to be taken care of.

\section{Aims and Objectives}

1. To evaluate the soft tissue parameters using Holdaway Analysis, for Southern Rajasthan Population in Various skeletal Malocclusion.

2. To compare the soft tissue parameter values pertaining to gender in between groups and within the groups.

3. To establish the tissue databases for each facial type.

\section{Material and Methods}

The lateral cephalometric radiographs of 80 healthy individuals [40 males \& 40 females] in the age range 20-55 years with Class I \&Class II skeletal malocclusions were retrieved from the department of orthodontics, Pacific Dental College, Udaipur. Soft tissue and skeletal features were traced on acetate sheets using craniographic methods [6].

TWO groups of each skeletal class comprised of 20 males and 20 females.

\section{Inclusion criteria}

- Permanent dentition

- Patient with class I and class II skeletal pattern.

\section{Exclusion criteria}

- Supernumerary teeth

- Para functional habits like mouth breathing and thumb sucking.

- Soft tissue and skeletal features were traced on acetate matt paper using $3 \mathrm{H}$ pencil and measured manually by the same operator.

- The images were classified into three skeletal classes based upon the ANB angle that indicates the positional relationship of the maxilla and mandible [7].

$\mathrm{A}=$ Deepest point on the line between the anterior nasal spine and the proshthion bones.

$\mathrm{N}=$ NASION, located on the suture between the frontal and nasal

$\mathrm{B}=$ POGONION, deepest point from line between the infradentale (apex of the alveolar bone between the left and right lower first incisors) and pogonion (Figure 1)

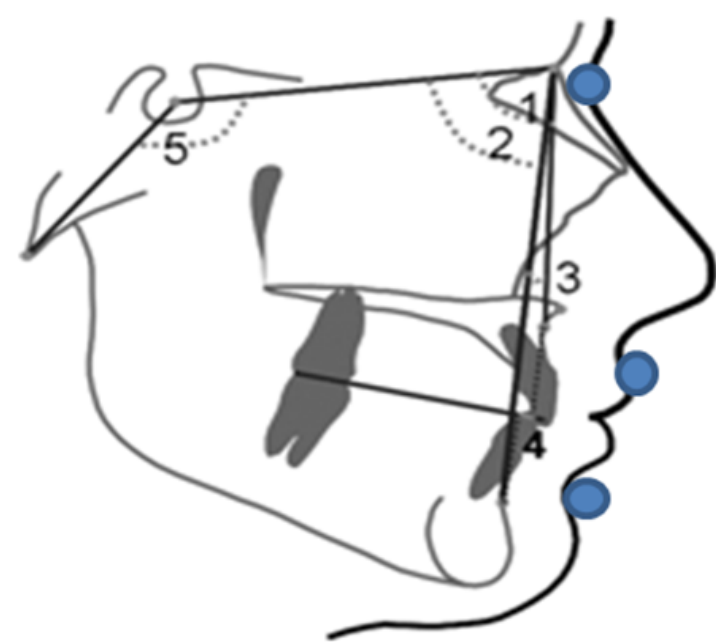

Figure 1: Two angular parameters

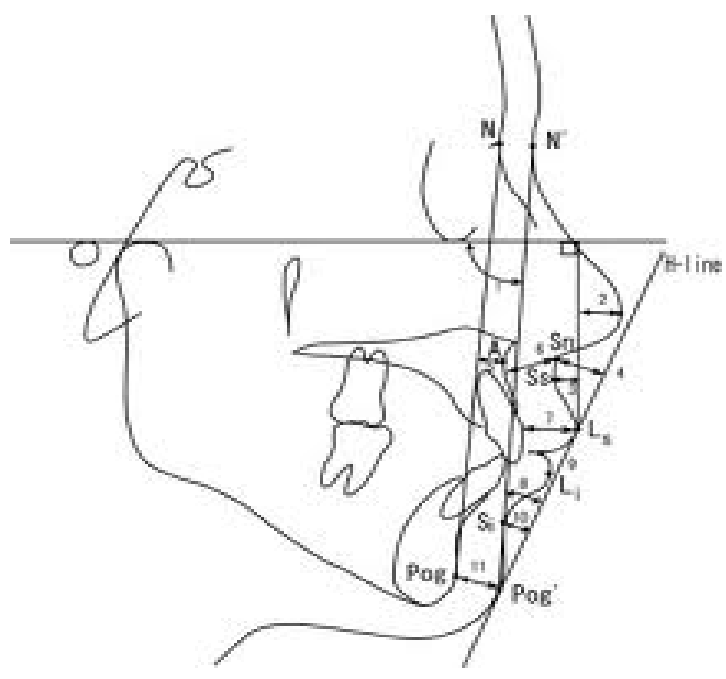

Figure 2: Nine linear parameters.

The two skeletal classes were classified as follows:

Class I: ANB angle 2-4 degree

Class II: ANB angle $>4$ degree

Cephalometric tracing showing evaluation of soft tissue landmarks using Holdaway soft tissue analysis [8]. Two angular parameters

[F angle]-Soft tissue facial angle

$\mathrm{H}$ angle

Nine linear parameters (Figure 2)

[NP]-Nose prominence

[SK C]-Skeletal profile convexity

[USD] -Superior sulcus depth

[SN-HLINE]-Soft tissue Subnasale to H line

[ULT] -Upper lip thickness 


\begin{tabular}{|c|c|c|c|c|c|c|c|}
\hline & Code & N & Mean & Std. Deviation & Std. Error Mean & t & Significance \\
\hline \multirow{2}{*}{ SNHLine } & 11 & 20 & 5.8500 & 1.30888 & 0.29267 & 0.001 \\
\cline { 2 - 9 } & 21 & 20 & 7.5000 & 1.60591 & 0.35909 & 3.562 & - \\
\hline \multirow{2}{*}{ H angle } & 11 & 20 & 18.9000 & 2.97180 & 0.66451 & 0.003 \\
\cline { 2 - 9 } & 21 & 20 & 22.0500 & 3.30032 & 0.73797 & 3.172 \\
\hline
\end{tabular}

Table 1: Comparison of SK Class1 Male VS SK Class2 male (sk-skeletal, code 11 class 1, code 21 class 2 male, $p$ significant>0.005).

\begin{tabular}{|c|c|c|c|c|c|}
\hline & Code & N & Mean & Std. Deviation & t \\
\hline \multirow{2}{*}{ NP } & 12 & 20 & 12.3000 & 1.65752 & -.936 \\
\cline { 2 - 5 } & 22 & 20 & 12.9500 & 2.62528 & \\
\hline \multirow{2}{*}{ SKConvexity } & 12 & 20 & 7.3500 & 1.75544 & 4.539 \\
\cline { 2 - 5 } & 22 & 20 & 3.4250 & 3.44611 \\
\hline
\end{tabular}

Table 2: Comparison of SK Class 1 Female VS SK Class 2 Female (sk-skeletal, code 12 class 1, code 22 class 2 female, p significant >0.005).

\begin{tabular}{|c|c|c|c|c|c|c|}
\hline Parameter & Group & Gender & N & \multicolumn{2}{|c|}{ Mean and SD } & P-value \\
\hline SK. convexity & Class1 & Male & 20 & 5.2 & 3.44 & $0.020[$ [ ] \\
\hline & & Female & 20 & 7.35 & 1.75 & \\
\hline
\end{tabular}

Table 3: Comparison of soft tissue parameters within the groups.

\begin{tabular}{|c|c|c|}
\hline Parameters & Skeletal class I & Holdaways norms \\
\hline NP & 12.65 & $14-24 \mathrm{~mm}$ \\
\hline SK.Convexity & 6.30 & -2 to $+2 \mathrm{~mm}$ \\
\hline SN-HLine & 6.05 & $3-7 \mathrm{~mm}$ \\
\hline USD & 3.85 & $1-4 \mathrm{~mm}$ \\
\hline ULT & 17.80 & $13-14 \mathrm{~mm}$ \\
\hline ULS & 3.78 & No norms \\
\hline LL-HLine & -2.44 & $1-4 \mathrm{~mm}$ \\
\hline LLS-HLine & 5.68 & No norms \\
\hline Pog-Pog & 11.23 & $10-12 \mathrm{~mm}$ \\
\hline H angle & 19.03 & $7-14$ degree \\
\hline F angle & 99.75 & $91 \pm 7$ degree \\
\hline
\end{tabular}

Table 4: Comparison of skeletal Class I norms with Holdaways Norms.

\begin{tabular}{|c|c|c|c|}
\hline Parameters & Chinese & $\begin{array}{c}\text { Southern Rajasthan } \\
\text { Population (present study }\end{array}$ & Turkish \\
\hline Facial angle & $92.5 \pm 7$ & $99.7 \pm 5$ & $91 \pm 7$ \\
\hline Nose prominence & $6 \pm 2$ & $12.6 \pm 5$ & $18 \pm 3$ \\
\hline USD & $5.5 \pm 1.5$ & $3.8 \pm 5$ & $3 \pm 1.5$ \\
\hline SN-H line & $9 \pm 1.5$ & $6 \pm 05$ & $5 \pm 3$ \\
\hline Skeletal profile convexity & $1.5 \pm 1.5$ & 6.30 & $0 \pm 2$ \\
\hline ULT & $15 \pm 1.5$ & $17.8 \pm 5$ & $17 \pm 2.5$ \\
\hline ULS & $1.5 \pm 0.5$ & $3.7 \pm 8$ & $16.6 \pm 2.4$ \\
\hline H-angle & $16 \pm 1.5$ & $19.0 \pm 3$ & $13 \pm 3$ \\
\hline Lower lip to h-line & $0.5 \pm 1$ & -2.44 & $0 \pm 2$ \\
\hline LL-H line & $4 \pm 1.5$ & $5.6 \pm 8$ & $0.03 \pm 1.9$ \\
\hline Soft tissue chin thickness & $9 \pm 1$ & $11.2 \pm 3$ & $13 \pm 2$ \\
\hline
\end{tabular}

Table 5: Comparison of soft tissue parameters of Rajasthan population with other ethnic groups.

[ULS]-Upper lip strain

[LL-H LINE]-Lower lip to H line

[LLS-H]-Inferior sulcus to $\mathrm{H}$ line

[POG-POG']-Soft tissue chin thickness [9].

Mean values of different parameters-were recorded, standard error was calculated and student ' $\mathrm{t}$ ' test was applied using SPSS version 17[10].

\section{Results}

Evaluation of soft tissue parameters in skeletal class I and class II (Tables 1-4).

\section{Discussion}

Orthodontics has the cephalometric analysis as a great diagnostic aid. Since the advent of the cephalostat, many authors have focused on establishing analyses that facilitate orthodontic planning. These studies were initially conducted in Caucasians, but it has been shown that different races have different 12 cephalometric standards, thus making it necessary to establish normative values for the different racial and ethnical groups $[11,12]$.

In the present study, evaluation of soft tissue parameters within the groups revealed skeletal convexity was more in females with skeletal class I. On inter group comparison, the values for $\mathrm{SN}-\mathrm{H}$ line and $\mathrm{H}$ angle were more in males with skeletal class II as compared to males with skeletal class I [13].

Skeletal convexity was more in females with skeletal class II as compared to females with skeletal class I. This shows that skeletal class II groups have a high positive value for skeletal convexity [14]. The $\mathrm{H}$ angle can be affected by the mandibular chin position. In the present study Rajasthan population with skeletal class II were observed to have a significantly protruded mandible [15]. The results of Skeletal class I AND II in the present study provide a set of average facial soft tissue depth measurement that may contribute to a more accurate reproduction of face on the skull. When values of Southern Rajasthan population were compared with Holdaway norms, we determined some differences regarding certain parameters between the two.

The results of skeletal class I in the present study reveal that values obtained for SK convexity, ULT, and H angle were more than that of Holdaways norms. This suggests that Southern Rajasthan population has a more convex profile and also protruded mandible with thick upper lip [16] (Table 5).

It is difficult to make a valuable comparison between our findings with those of other studies as various other analyses have been used to estimate STT. No studies-using Holdaways parameters, carried out in various skeletal classes, in other ethnic groups were found in the literature to compare the present study.

Hence, these results highlight the fact that a thorough anthropological analysis of the skull, including an assessment of the skeletal classes and peculiarities of occlusion, is necessary before starting a craniofacial reconstruction. A comparison between males and females disclosed that males had significantly higher upper lip sulcus depth, greater upper lip thickness and soft tissue chin thickness. Similar findings were reported [17].

Basciftci et al. concluded the difference regarding upper lip sulcus depth was statistically insignificant. Genecov et al., measured upper lip 
sulcus depth in relation to subnasale vertical line, also reported larger value in young adult males as compared to females. When the results of the current study were compared with those performed on other populations, similar findings were reported regarding the insignificant difference between men and women for $\mathrm{H}$ angle.

On the other hand, our findings regarding soft tissue facial angle disagree with those reported by Hashim and Al Baracati (16) who showed a significantly higher value in females than males.

Manar Y Abdul-Qadir determines cephalometric standards for Iraqi adults using Holdaway soft tissue analysis. The sample comprised 60 individual ( 31 males and 29 females), aged between 18-23years. Ten linear and tow angular parameters were measured on lateral cephalometric radiographs, using the definitions provided by Hold away. For each variable mean and SD were calculated, authors were found that Iraqi adults showed a more obtuse $\mathrm{H}$ angle, less nose prominence, more upper lip strain, more skeletal convexity, and greater soft tissue chin thickness. In addition, a comparison between males and females revealed a significant sexual dimorphism for upper lip sulcus depth, upper lip thickness, basic upper lip thickness, and soft tissue chin thickness [18].

\section{Scope for Future Studies}

Further studies could be carried out using much larger samples. In judging the acceptable esthetics, a bigger panel of judges including other professionals and lay persons could be employed.

Subtenly has recommended that the analysis of the soft tissue should be taken into consideration for the proper evaluation of an underlying skeletal discrepancy because of individual differences in soft tissue thickness [19].

\section{Conclusions}

The present study reported differences in mean facial soft tissue thickness between two skeletal classes in southern Rajasthan adult population. A larger study is needed to obtain a more accurate comparison although the present sample was small, trends in interrelationship thickness for each skeletal class was apparent. This study focused on evaluating soft tissue profile of RAJASTHHANI adults according to Holdaway analysis. The results revealed that some measurements were different from those proposed by Holdaway, including; $\mathrm{H}$ angle, nose prominence, upper lip strain, skeletal convexity, and soft tissue chin thickness. These differences disclose the importance of using normative data established for Iraqi individuals in formulating orthodontic diagnosis and treatment plan. When the differences between the sexes were explored, only four variables showed statistically significant difference. Men possessed more upper lip curvature, greater upper lip and basic upper lip thickness, and thicker soft tissue chins [20].

\section{References}

1. William Arnett $\mathrm{G}$, Facial keys to orthodontic diagnosis and treatment planning.

2. Manar Y Abdul-Qadir (2008) Evaluation of Holdaway Soft Tissue Analysis for Iraqi Adults with Class I Normal Occlusion Al-Rafidain Dent J 8: 2.
3. Utsuno H, Kageyama T, Uchida K, Yoshino M, Oohigashi S, et al. (2010) Pilot study of facial soft tissue thickness differences among three skeletal classes in Japanese females. Forensic Sci Int 195: 165.

4. Cavanagh D, Steyn M (2011) Facial reconstruction: soft tissue thickness values for South African black females. Forensic Sci Int 206: 215.

5. Holdaway RA (1983) A soft tissue cephalometric analysis and its use in orthodontic treatment planning. Part I Am J Orthod 1-28

6. Angle Orthod Subtelny JD The Soft Tissue Profile, Growth and Treatment Changes. 31: 105-122

7. Peck H, Peck S (1970) A concept of facial esthetics. Angle Orthod 40: 284-318

8. Mohamed el-hadidy (2007) Cephalometric Analysis for Evaluating the Profile Nasal Morphology in Egyptian Adults Egypt, J Plast Reconstr Surg, 3: July: 243-249.

9. Abdul-Qadir MY, Al-Dawoody AD, Agha NF (2008) Evaluation of Holdaway Soft tissueanalysis for Iraqi Adults with Class I Normal Occlusion ,University of Mosul Dent J; 8: 231-237.

10. Arshad hameed, Soft tissue facial profile analysis in patients with class i and class ii skeletal pattern visiting children's hospital, lahore pakistan oral \& dental journal 28: 2

11. loi H, Nakata S, Nakasima A, Counts AL (2007) Comparison of cephalometric norms between Japanese and Caucasian adults in antero-posterior and vertical dimension. Eur J Orthod 29: 493-499.

12. Bass NM (2003) Measurement of the profile angle and the aesthetic analysis of the facial profile. J Orthod 30: 3-9.

13. Fernández-Riveiro $P$, Smyth-Chamosa $E$, Suárez-Quintanilla $D$, SuárezCunqueiro M (2003) Angular photogrammetric analysis of the soft tissue facial profile. Eur J Orthod 25: 393-399.

14. Erbay EF, CaniklioÄŸlu CM, Erbay SK (2002) Soft tissue profile in Anatolian Turkish adults: Part I. Evaluation of horizontal lip position using different soft tissue analyses. Am J Orthod Dentofacial Orthop 121: 57-64.

15. Sutter RE Jr, Turley PK (1998) Soft tissue evaluation of contemporary Caucasian and African American female facial profiles. Angle Orthod 68: 487496.

16. El Faituri H, Rani MS (1994) Cephalometric norms for Libyan population. Arab Dent J. 1: 35-47.

17. Al-Sayagh NM (1999) Dentoskeletal analysis and facial types of Iraq adults in Mosul City with Class one normal occlusion (a lateral radiographic cephalometric study). MSc. Thesis. College of Dentistry. University of Mosul.

18. Thais Maria (2013) Comparative study of the soft tissue of young JapaneseBrazilian, Caucasian and Mongoloid patients, Dental Press J Orthod. 2: 116-24.

19. Taki AA, Oguz F, Abuhijleh E (2009) Facial soft tissue values in Persian adults with normal occlusion and well-balanced faces. Angle Orthod 79: 491-494.

20. Peeyush Mehta, Tripti Tikku, Rohit Khanna, R P Maurya (2010) Holdaway's soft tissue cephalometric norms for the population of Lucknow, India, Journa of Oral Health Research. 